\title{
Study of Patient Ventilator Dyssynchrony, Causes and Effect on Weaning in Mechanically Ventilated Patient in Respiratory Intensive Care Unit, Observational Study
}

\author{
Moustafa Abd El Hafez Zedan, Abdalla Soliman Ayoub, Ameen A Hegazy* \\ Department of Chest disease and * Department of Internal Medicine, Faculty of Medicine, Al Azhar \\ University, Cairo, Egypt
}

Corresponding author: Moustafa Abd El hafez Zedan, Phone: (020) 01003096479, E-Mail: mostafa.zedan74@yahoo.com

\begin{abstract}
Background: Obtaining the comfort in intensive care unit to patients is important. Patient-ventilator dyssynchrony is a big problem in respiratory ICU and when a chest physician facing it in ICU must be aware about causes and deleterious effects on the patients, so study of causes and its impact on weaning outcomes is very important.

Aim of the work: was to study patient ventilator dyssynchrony, causes and effect on weaning in mechanically ventilated patients in respiratory ICU.

Patients and Methods: Fifty patients were included in the study admitted at Sayed Galal, Al-Azhar University Hospital during period from May 2014 - December 2017 in RICU, all patients underwent the following ,Full history taking, Genral ,Local examinations, Monitoring for occurance of agitation, patient ventilator dyssynchrony, and duration of weaning, and observation for the cause of the problem. Exclusion criteria, shock patient with haemodynamic instability.

Results:The diagnosis of cases 18 COPD, 9 pneumonia, 8 bronchectasis, 4 Ild (interstitial lung disease), 6 OHS(obesity hypoventilation syndrome) and 5 pulmonary edema. Patients with dyssncrony have more duration of weaning $5.5455 \pm .90453$ days than patients without dyssnchrony have duration of weaning 3.8125 \pm .83417 days with significant difference. And the dyssnchrony group have more duration of ICU stay time (days) with $9.8485 \pm 1.03444$ days than the patients without dyssnchrony have duration of weaning $8.0625 \pm .85391$ days with significant difference .

Conclusion: Patient ventilator asynchrony occurs frequently, it is sensitive to ventilator settings and artificial airway problem, increased secretions, bronchospasm, alteration in body posture and seems to be associated with prolongation of weaning time.
\end{abstract}

Key words: Patient ventilator dyssnchrony, weaning

\section{INTRODUCTION:}

Patient ventilator asynchrony (PVA) is a mismatch between patient and ventilator assisted breaths and the ventilator's ability to meet the patient's flow demand ${ }^{(1)}$. The Patientventilator interaction occur two respiratory pumps firstly patient's pulmonary system controlled by the neuromuscular system and affected by the mechanical characteristics of the lungs and thorax, and secondly the ventilator controlled by the ventilator settings and the function of the flow valve. Anything that affects the harmony between the 2 pumps results in asynchrony ${ }^{(2)}$. PVA is common in the intensive care unit (ICU) with up to $25 \%$ ventilated patients exhibiting asynchronous ventilator interaction ${ }^{(3)}$.

The aim of the work was to study patient ventilator dyssynchrony, causes and effect on weaning in mechanically ventilated patients in respiratory ICU.

\section{Patients and Methods:}

This study included a total of fifty patients with respiratory diseases attending at Respiratory Intensive Care Unit, Sayed Galal, Al-Azhar University Hospital. Approval of the ethical committee and a written informed consent from all the subjects were obtained. This study was conducted in period from May 2014- December 2017.

Patients' age ranged from 34-63 years and includes 33 males and 17 females. All patients were subjected to the following; full history taking, general and local examination, monitoring for occurrence of agitation and /or 
respiratory distress, and duration of weaning and observation for the cause of the problem. The patient is considered suffer from dyssnchrony with the mechanical ventilator when there is agitation and /or respiratory distress. As the patient is intubated and no speaking to express what he feels, the chest physician in ICU must depend on signs to recognize agitation and respiratory distress. The patient was considered agitated if irregular patient movements and/or facial signs of pain, discomfort or distress. The patient was considered with respiratory distress if there is tachypnea, nasal flaring, excessive sweating, use of the accessory muscles of respiration (scalene and sternomastoids), intercostal retractions, abdominal paradox, tachycardia, cardiac arrhythmias. All patient was put on mechanical ventilation on assisted controlled mode and when the patient become ready to be weaned by assessment of all weaning criteria, the duration of weaning start from beginning of the weaning until the patient was extubated and using a pressure support ventilation with apnea back up in patient of the study, artificial airway problems diagnosed by clinical auscultation of both lung and by radiological assessment and follow up monitoring for the airway pressure on mechanical ventilation and airway secretion is considered increases if more than $30 \mathrm{~cm} \mathrm{h2o} \mathrm{is} \mathrm{present,} \mathrm{bronchospasm} \mathrm{by}$ auscultation, Alteration in body posture (the arrangement of the body and its limbs) when the patient start any movement and noted by close observation and revision of all initial ventilator set is mandatory in every cases and specially in cases of dyssnchrony and record if air adequate or not, and revision of inspiratory flow setting and observation for presence of flow starvation on graphics on. The flowstarved patient's attempts to breathe deeply leads to a drop-in airway pressures, and this can show up as an inward buckling on the initial part of the ascending limb of the pressure wave form and flow starvation during PSV results in a loss of the usual peak on the flow-time waveform. During PSV, the normal flow-time scalar shows an early peak followed by a ramping decline followed by a steeper fall and Flow starvation on the pressure-volume loop manifests as an indentation on the inspiratory segment of the loop ${ }^{(4)}$. Auto peep was diagnosed by routinely check for auto-PEEP by inspecting the end of the expiratory flow waveform and by measuring auto-PEEP (4).

Exclusion criteria included shock patient with hemodynamic instability.

Statistical analysis: Statistical analysis was carried out using the SPSS computer package version 21.0 (SPSS Inc., Chicago, IL, USA). For descriptive statistics; the mean \pm SD was used for quantitative variables while the number and percentage were used for qualitative variables. independent samples t-test was applied in order to assess the differences in means of quantitative variables. The statistical methods were verified, assuming a significant level of $\mathrm{p}<0.05$.

\section{RESULTS:}

In this study the diagnosis of cases were 18 COPD, 9 pneumonia, 8 bronchectasis, 4 Ild (interstitial lung disease), 6 OHS (obesity hypoventilation syndrome) and 5 pulmonary edema. All these cases with indication respiratory failure to mechanical ventilation table (1).

Patients were classified into two groups: Group 1; Dyssynchrony: 34 patients (68\%) and Group 2; No dyssnchrony|: 16 patients (32\%). The dyssnchrony group included 11 COPD, 8 bronchiectasis, 3 ILD (interstitial lung disease), 3 OHS and 4 pulmonary edema patients table(2).

Artificial airway problem in $36 \%$ from cases of study and is present mostly in cases of bronchiectasis $62.5 \%$ and pneumonia $55.5 \%$, COPD $38.8 \%$, ILD $25 \%$ and Pulmonary edema $20 \%$. The increased secretions occurred in $40 \%$ of cases, bronchospasm in $36 \%$ of cases and alteration in body posture in $16 \%$ table (3)

The Inadequate initial ventilator support cause dyssnchrony in $34 \%$ of cases and Improper inspiratory flow setting cause dyssnchrony in $28 \%$ of cases and Auto peep in $20 \%$ table(4)

In this study the dyssnchrony group 1 have more duration of weaning mean \pm SD 5.5455 \pm .90453 days than group 2 have less duration of weaning $3.8125 \pm .83417$ days with significant difference table (5)

The dyssnchrony group 1 had more duration of ICU stay time (days) with mean \pm SD $9.8485 \pm 1.03444$ days and group 2 had less duration of weaning $8.0625 \pm .85391$ days with significant difference table (5) 
Table (1): Cases included in the study

\begin{tabular}{|c|c|c|c|}
\hline Cases & Number & Total \\
\hline COPD & $\mathbf{1 8}$ & $\mathbf{3 2}$ & \multirow{2}{*}{50} \\
\hline Pneumonia & $\mathbf{9}$ & $\mathbf{1 8}$ & \\
\hline Bronchectasis & $\mathbf{8}$ & $\mathbf{1 6}$ & \\
\hline Ild (interstitial lung disease ) & 4 & $\mathbf{8}$ & \\
\hline $\begin{array}{c}\text { OHS( obesity hypoventilation } \\
\text { syndrome ) }\end{array}$ & $\mathbf{6}$ & $\mathbf{1 0}$ & \\
\hline Pulmonary oedema & $\mathbf{5}$ & & \\
\hline
\end{tabular}

Table ( 2) Classification of patients into two groups

\begin{tabular}{|c|c|c|c|}
\hline & $\begin{array}{c}\text { Group 1 } \\
\text { Dyssynchrony }\end{array}$ & $\begin{array}{c}\text { Group2 No } \\
\text { dyssnchrony }\end{array}$ & Total \\
\hline Number & $\mathbf{3 4}$ & $\mathbf{1 6}$ & $\mathbf{5 0}$ \\
\hline Percentage & $\mathbf{6 8} \%$ & $\mathbf{3 2} \%$ & $\mathbf{1 0 0 \%}$ \\
\hline COPD & $\mathbf{1 1}$ & $\mathbf{7}$ & $\mathbf{1 8}$ \\
\hline Pneumonia & $\mathbf{5}$ & $\mathbf{4}$ & $\mathbf{9}$ \\
\hline Bronchectasis & $\mathbf{8}$ & $\mathbf{8}$ & $\mathbf{4}$ \\
\hline $\begin{array}{c}\text { ILD (interstitial } \\
\text { lung disease ) }\end{array}$ & $\mathbf{3}$ & $\mathbf{3}$ & $\mathbf{6}$ \\
\hline $\begin{array}{c}\text { OHS( obesity } \\
\text { hypoventilation } \\
\text { syndrome ) }\end{array}$ & $\mathbf{3}$ & 1 & 5 \\
\hline Pulmonary oedema & $\mathbf{4}$ & & \\
\hline
\end{tabular}

Table (3) Patient-Related Causes of patient ventilator dysynchroy among studied group .

\begin{tabular}{|c|c|c|c|c|c|c|c|c|c|}
\hline & \multicolumn{2}{|c|}{$\begin{array}{c}\text { Artificial } \\
\text { airway } \\
\text { problem }\end{array}$} & \multicolumn{2}{|c|}{$\begin{array}{l}\text { Increased } \\
\text { secretions }\end{array}$} & \multicolumn{2}{|c|}{ Bronchospasm } & \multicolumn{2}{|c|}{$\begin{array}{l}\text { Alteration } \\
\text { in body } \\
\text { posture }\end{array}$} & \multirow{2}{*}{$\begin{array}{c}\text { Num } \\
\text { ber } \\
\text { of } \\
\text { cases }\end{array}$} \\
\hline & $\mathbf{N}$ & $\%$ & $\mathbf{N}$ & $\%$ & $\mathbf{N}$ & $\%$ & $\mathbf{N}$ & $\%$ & \\
\hline $\begin{array}{l}\text { Number of event in } \\
\text { relation to total cases }\end{array}$ & 18 & 36 & 20 & 40 & 18 & 36 & 8 & 16 & 50 \\
\hline COPD & 7 & 38.8 & 5 & 27.7 & 8 & 44.4 & 3 & 16.6 & 18 \\
\hline Pneumonia & 5 & 55.5 & 4 & 44.4 & 2 & 22.2 & 0 & 0 & 9 \\
\hline Bronchectasis & 5 & 62.5 & 8 & 100 & 3 & 37.5 & 0 & 0 & 8 \\
\hline $\begin{array}{c}\text { Ild (interstitial lung } \\
\text { disease ) }\end{array}$ & 1 & 25 & 0 & $\mathbf{0}$ & $\mathbf{0}$ & $\mathbf{0}$ & 0 & $\mathbf{0}$ & 4 \\
\hline $\begin{array}{c}\text { OHS( obesity } \\
\text { hypoventilation } \\
\text { syndrome ) }\end{array}$ & $\mathbf{1}$ & 16.6 & 1 & 16.6 & 2 & 33.3 & 2 & 33.3 & 6 \\
\hline Pulmonary oedema & 1 & 20 & 2 & 40 & 3 & 60 & 3 & 60 & 5 \\
\hline
\end{tabular}


Table (4) Ventilator related causes among cases.

\begin{tabular}{|l|l|l|l|l|l|l|l|}
\hline & $\begin{array}{l}\text { Inadequate } \\
\text { initial } \\
\text { ventilatory } \\
\text { support }\end{array}$ & \multicolumn{2}{l|}{$\begin{array}{l}\text { Improper } \\
\text { inspiratory flow } \\
\text { setting }\end{array}$} & \multicolumn{2}{l}{ auto-PEEP } & $\begin{array}{l}\text { Total } \\
\text { number } \\
\text { of cases }\end{array}$ \\
\hline & N & $\%$ & N & $\%$ & N & $\%$ & N \\
\hline $\begin{array}{l}\text { Number of event in } \\
\text { relation to total cases }\end{array}$ & 17 & 34 & 14 & 28 & 10 & 20 & 50 \\
\hline COPD & 6 & 33 & 5 & 27 & 4 & 22 & 18 \\
\hline Pneumonia & 2 & 22 & 1 & 11 & 1 & 11 & 9 \\
\hline Bronchectasis & 3 & 37 & 2 & 25 & 1 & 12 & 8 \\
\hline $\begin{array}{l}\text { Ild (interstitial lung } \\
\text { disease ) }\end{array}$ & 2 & 50 & 2 & 50 & 2 & 50 & 4 \\
\hline $\begin{array}{l}\text { OHS( obesity } \\
\text { hypoventilation } \\
\text { syndrome ) }\end{array}$ & 2 & 33 & 2 & 33 & 1 & 16 & 6 \\
\hline Pulmonary oedema & 2 & 40 & 2 & 40 & 1 & 20 & 5 \\
\hline
\end{tabular}

Table (5):Comparison between two groups in duration of weaning and ICU stay

\begin{tabular}{|l|l|r|l|r|}
\hline & Group & \multicolumn{1}{|c|}{$\begin{array}{c}\text { Mean } \pm \\
\text { Std. Deviation }\end{array}$} & $\begin{array}{c}\text { P } \\
\text { value }\end{array}$ \\
\hline weaning & group 1 (dysynchrony) & 34 & $5.5455 \pm .90453$ & 0.001 \\
time(days) & group 2 & 16 & $3.8125 \pm .83417$ & \\
\hline ICU stay & group 1 (dysynchrony) & 34 & $\mathbf{9 . 8 4 8 5 \pm 1 . 0 3 4 4 4}$ & $\mathbf{0 . 0 0 1}$ \\
time(days ) & group 2 & 16 & $8.0625 \pm .85391$ & \\
\hline
\end{tabular}

\section{DISCUSSION:}

In this study fifty patients with respiratory diseases were admitted in respiratory ICU in Chest Department in Sayed Galal; Al Azhar University Hospitals during period from May 2014- December 2017. All patients were on mechanical ventilation as a line of treatment and according to need of the patient. Patients were observed for the occurrence of agitation or respiratory distress and observation for the cause of this condition and collection of data and analysis for the cause. All these cases admitted to respiratory ICU with indication to mechanical ventilation respiratory failure table (1) and by clinical observation for occurrence of dessynchrony the patients were classified into two groups: Group 1 Dyssynchrony 34 patients 68\%, Group2 No dyssnchrony 16 patients $32 \%$ and the cases in the dyssnchrony group include COPD in 11 patient ,bronchiectasis in 8, ILD in 3 patients , OHS in 3 patients and pulmonary oedema in 4 patients Table (2) and the causes of dyssnchrony are endotracheal tube problems mainly obstruction in $36 \%$ from cases of study and this occure mostly in cases of bronchiectasis $62.5 \%$ and pneumonia $55.5 \%$, COPD $38.8 \%$, ILD 25\% and Pulmonary edema $20 \%$, the increased secretions occur in $40 \%$ of cases. This in agreement with Divatia and Bhowmick $^{(5)}$ they found airway obstruction occur during mechanical ventilation and considered one of complication (5). Bronchospasm occurred in $36 \%$ of cases and Alteration in body posture the arrangement of the body and its limbs in $16 \%$ table (3)

Revision of the initial ventilator settings was done when the criteria of dyssynchrony present and change in ventilator setting was 
done according to the clinical finding and ventilator parameter and the following was present, the inadequate initial ventilatory support was noted in 17 cases $34 \%$ of cases and after change in initial ventilator setting the patient improved clinically and become synchronous with the ventilator and the inadequate initial ventilatory support occurred in cases with COPD 33\%, interstitial lung disease $50 \%$, pneumonia $22 \%$,bronchectasis $37 \%$,OHS33\% ,pulmonary edema $40 \%$ table (4) and these result in agreement with results obtained by Matthieu $\boldsymbol{e t}$ al. they observe the mechanically ventilated patients for presence of dyspnea and they found dyspnea responded to changes in ventilator settings in $35 \%$ of dyspneic patients in the study ${ }^{(6)}$.

The dyssnchrony group 1 have more duration of weaning mean \pm SD $5.5455 \pm \mathbf{. 9 0 4 5 3}$ days than group 2 have less duration of weaning $\mathbf{3 . 8 1 2 5}+\mathbf{8 3 4 1 7}$ days with significant difference table (5)

The dyssnchrony group 1 have more duration of ICU stay time(days ) with mean \pm SD $\mathbf{9 . 8 4 8 5} \pm \mathbf{1 . 0 3 4 4 4}$ days than group 2 have less duration of weaning $\mathbf{8 . 0 6 2 5} \pm .85391$ days with significant difference table (5), and this in agreement with Richard $\boldsymbol{e t}$ al. they reported that the presence and severity of asynchrony is accompanied with prolonged mechanical ventilation, longer ICU stay, and mortality ${ }^{(7)}$.

\section{Conclusion:}

Patient-ventilator synchrony is a complex issue that includes patient factors, ventilator factors, interface, mode, ventilator settings, and the patient's sensation of dyspnea. Sedation and analgesia also play an important role.

\section{Reference:}

1-Sassoon CS, Foster GT (2001): Patientventilator asynchrony. Curr Opin Crit Care, 7:28-33.

2-Jon $O$ and Kenneth D (2005): Using Ventilator Graphics to Identify Patient-Ventilator Asynchrony.Respiratory care, 50(2): 202-234.

3-Thille AW, Rodriguez $P$, Cabello B, Lellouche F, Brochard L (2006): Patientventilator asynchrony during assisted mechanical ventilation. Intensive Care Med., 32:1515-1522.

4- Ashfaq H (2010): patient ventilator asynchrony. Understanding Mechanical Ventilation A Practical Handbook., Second Edition, Springer-Verlag London Limited .

5- Divatia J, Bhowmick K (2005): Complications of endotracheal intubation and other airway management procedures. Indian J. Anaesth., 49(4):308-318.

6- Matthieu S, Alexandre D, Andrea P, Raphae 1, Jerome A, Shidasp S, Capucine M,Thomas S and Tarek S (2011): Dyspnea in mechanically ventilated critically ill patients. Crit Care Med., 39: 9.

7-Richard D, Thomas C and Bryce R (2013): Asynchrony and Dyspnea. Respiratory care, 58:6. 